\title{
Épocas de semeadura, cultivares e densidades de plantas para algodão adensado em segunda safra ${ }^{1}$
}

\author{
Alexandre Cunha de Barcellos Ferreira ${ }^{2}$, Ana Luiza Dias Coelho Borin², \\ Giovani Greigh de Brito ${ }^{3}$, João Luis da Silva Filho' ${ }^{2}$, Julio Cesar Bogiani ${ }^{4}$
}

\begin{abstract}
Sowing date, cultivars and plant

density for second crop narrow row cotton

The second crop narrow row cotton under rainfed conditions, after soybean or common bean harvest, has increased in the Midwest Brazilian Savannah. This change in sowing date exposes cotton plants to adverse environmental conditions. This study aimed at evaluating the effect of cotton cultivars, plant densities and sowing dates on cotton yield. The experiments were conducted over three consecutive years. In each year, the treatments were two sowing dates (second half of January and first half of February), cultivars (early and mid-cycle) and plant densities (8.9-33.3 plants $\left.\mathrm{m}^{-2}\right)$. Cotton was sowed in the second crop, after the early soybean harvest. In each sowing date, experiments were conducted in a split-plot randomized blocks design, with cultivars arranged in plots and densities in subplots. Cotton yield in the second crop growth season was little affected by plant densities and cultivars. Late sowing reduced plant height, number of bolls per unit area and cotton lint yield. In the second sowing date, lint yield decreased nearly $25 \%, 17 \%$ and $41 \%$, respectively in 2009, 2010 and 2011. Sowing date is the most important factor for cotton production in a second crop.
\end{abstract}

KEY-WORDS: Gossypium hirsutum L. r. latifolium; off-season cultivation; plant population.

\section{INTRODUÇÃO}

No Cerrado do Centro-Oeste brasileiro, o algodoeiro herbáceo (Gossypium hirsutum L. var. latifolium) é tradicionalmente semeado de novembro a dezembro e colhido de junho a julho. Nessa condição de cultivo, a disponibilidade de água e a temperatura são adequadas ao seu estabelecimento e desenvolvimento, diminuindo os riscos de perda de produtividade devido a déficit hídrico, durante o período reprodutivo.

\section{RESUMO}

O cultivo de algodoeiro adensado em segunda safra, em ambiente não irrigado, após soja ou feijão, tem aumentado no Cerrado do Centro-Oeste brasileiro. Com essa mudança de época de semeadura, as plantas de algodão estão mais expostas a condições climáticas adversas. Objetivou-se avaliar o efeito de cultivares, densidades de plantas e épocas de semeadura sobre a produção de algodão. Os experimentos foram realizados em três anos consecutivos. Em cada ano, os tratamentos foram constituídos por duas épocas de semeadura (segunda quinzena de janeiro e primeira quinzena de fevereiro), cultivares (ciclo precoce e médio) e densidades de plantas (8,9-33,3 plantas $\left.\mathrm{m}^{-2}\right)$. O algodão foi semeado em segunda safra, após a colheita de soja precoce. Em cada época de semeadura, os experimentos foram instalados no delineamento de blocos ao acaso, em parcelas subdivididas, com o fator cultivar disposto na parcela e a densidade na subparcela. A produtividade do algodoeiro em segunda safra foi pouco influenciada pelas densidades de plantas e cultivares. A semeadura tardia do algodoeiro reduziu a altura de plantas, número de capulhos por área e produtividade de fibra. Com o atraso na data de semeadura, a produtividade de fibra diminuiu aproximadamente $25 \%, 17 \%$ e $41 \%$, respectivamente em 2009, 2010 e 2011. O fator mais determinante para o cultivo do algodoeiro em segunda safra é a época de semeadura.

PALAVRAS-CHAVE: Gossypium hirsutum L. r. latifolium; safrinha; população de plantas.

No cultivo em safra, predominam espaçamentos que variam de $76 \mathrm{~cm}$ a $90 \mathrm{~cm}$ entre as fileiras, com seis a dez plantas por metro. Entretanto, nos últimos anos, tem aumentado a semeadura do algodão em segunda safra, também conhecida como safrinha, após o cultivo e colheita de soja de ciclo precoce. No Estado de Mato Grosso, maior produtor brasileiro de algodão, a área cultivada em 2014/2015 foi de 564,2 mil ha, sendo que $76 \%$ ocorreu em segunda safra (IMEA 2015).

1. Trabalho recebido em jul./2015 e aceito para publicação em nov./2015 (http://dx.doi.org/10.1590/1983-40632015v4536869).

2. Empresa Brasileira de Pesquisa Agropecuária (Embrapa Algodão), Santo Antônio de Goiás, GO, Brasil.

E-mails: alexandre-cunha.ferreira@embrapa.br, ana.borin@embrapa.br, joao.silva-filho@embrapa.br.

3. Empresa Brasileira de Pesquisa Agropecuária (Embrapa Clima Temperado), Pelotas, RS, Brasil. E-mail: giovani.brito@embrapa.br. 4. Empresa Brasileira de Pesquisa Agropecuária (Embrapa Algodão), Luís Eduardo Magalhães, BA, Brasil.

E-mail: julio.bogiani@embrapa.br. 
A produtividade do algodoeiro é influenciada pela temperatura, radiação solar e disponibilidade de água (Wells \& Stewart 2010), fatores que podem ser alterados em função da época de semeadura. Além disso, variações no arranjo de plantas interferem no crescimento e desenvolvimento do algodoeiro.

O ajuste da densidade de plantas pode facilitar a condução da lavoura e até incrementar a produtividade (Silva et al. 2006). Espaçamentos estreitos podem reduzir o ciclo do algodoeiro e o número de aplicações de defensivos para o controle de pragas e doenças (Jost \& Cothren 2001). Porém, em maiores populações de plantas, o ambiente pode se tornar propício à incidência de doenças fúngicas. $\mathrm{O}$ aumento da densidade de plantas também favorece a queda de botões florais, flores e frutos novos e, com isso, reduz-se o número de capulhos e a produção individual da planta (Boquet 2005).

Se, por um lado, a produção por planta é menor, o maior número de plantas por área propicia produtividade semelhante ou superior à obtida em menores densidades de plantas, dependendo das condições de cultivo. Em espaçamentos entre fileiras inferiores a $0,51 \mathrm{~m}$ e com altas populações, Clawson et al. (2006) observaram que o número de capulhos por planta reduziu, mas a produtividade não foi alterada em virtude do maior número de plantas por área. Jost \& Cothren (2001) observaram que populações de $122.000-450.000$ plantas ha-1 não afetaram a produtividade e a qualidade da fibra. Porém, a maturidade e a colheita do algodão foram antecipadas nas maiores populações.

Alguns estudos evidenciam que a produtividade de fibra do algodoeiro aumenta quando este é cultivado de forma adensada, em comparação aos espaçamentos e populações convencionais, mas existem muitas variações nos resultados entre experimentos, anos e cultivares (Lamas et al. 2005, Clawson et al. 2006).

As cultivares de ciclo precoce, médio e tardio diferem quanto ao porte e arquitetura, sendo que as tardias apresentam mais nós vegetativos, porte mais elevado, maior período de transição entre as fases vegetativa e reprodutiva (Wells \& Stewart 2010) e ciclo mais longo. Acredita-se que cultivares de algodoeiro com arquitetura compacta, ou seja, com menor número de nós da haste principal, ramos produtivos mais curtos e ciclo menor, se ajustem melhor às condições de cultivo adensado, porém, isso foi pouco estudado no Cerrado brasileiro, visando ao cultivo em segunda safra.

A semeadura do algodão em segunda safra ocorre quase que simultaneamente à colheita da soja, que pode demorar em função de chuvas ao final do ciclo ou devido à semeadura mais tardia da soja. Assim, a hipótese do presente trabalho é que a época de semeadura do algodoeiro, dependendo da população de plantas e da cultivar, pode afetar a produtividade e indicar a viabilidade do seu cultivo adensado em segunda safra.

Objetivou-se avaliar o efeito de épocas de semeadura, cultivares e densidades de planta sobre a altura, componentes de produção e produtividade de fibra de algodoeiro, quando cultivado em segunda safra no Cerrado, em ambiente não irrigado.

\section{MATERIAL E MÉTODOS}

Os experimentos foram conduzidos nos anos de 2009, 2010 e 2011, no município de Montividiu

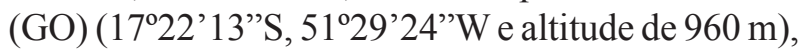
em condição não irrigada, em duas épocas de semeadura em segunda safra (segunda quinzena de janeiro e primeira quinzena de fevereiro). Em cada época, o experimento foi instalado no delineamento de blocos ao acaso, em parcelas subdivididas, com o fator cultivar disposto na parcela e o fator densidade na subparcela (Tabela 1). Foram estudadas as cultivares FM 966 e FMT 523, de porte baixo e ciclo precoce, e a BRS 293, de ciclo e porte médios. Em cada ano, as cultivares foram testadas nas duas épocas de semeadura.

O clima da região, conforme a classificação de Köppen, é do tipo Aw, com uma estação seca entre maio e setembro e uma estação chuvosa de outubro

Tabela 1. Épocas de semeadura, cultivares e densidades de plantas, nos três anos de condução do experimento (Montividiu, GO).

\begin{tabular}{|c|c|c|c|c|c|c|c|c|c|}
\hline Ano & \multicolumn{2}{|c|}{ Épocas } & \multicolumn{3}{|c|}{ Cultivares } & \multicolumn{4}{|c|}{ Densidades (plantas $\mathrm{m}^{-2}$ ) } \\
\hline 2009 & $23 / 01$ & $13 / 02$ & FM 966 & & BRS 293 & 8,9 & 13,3 & 17,8 & 22,2 \\
\hline 2010 & $23 / 01$ & $05 / 02$ & FM 966 & BRS 293 & FMT 523 & 17,8 & 24, & & 31,1 \\
\hline 2011 & $28 / 01$ & $11 / 02$ & FMT 523 & & BRS 293 & 13,3 & 20,0 & 26,6 & 33,3 \\
\hline
\end{tabular}


a abril. As precipitações pluviais durante a condução dos trabalhos constam na Figura 1.

Cada subparcela foi composta de oito linhas espaçadas entre si em 0,45 m, com cada linha apresentando 5,0 $\mathrm{m}$ de comprimento. A semeadura do algodão foi realizada mecanicamente, em área cultivada previamente com soja precoce. Na linha de semeadura, foram dispostas 25 sementes $\mathrm{m}^{-1} \mathrm{e}$, para o ajuste das densidades desejadas, foi realizado desbaste aos 12 dias após a emergência dos algodoeiros.

Nos três anos avaliados, previamente à instalação dos experimentos, foram coletadas amostras de solo, classificado como Latossolo Vermelho-Amarelo (Santos et al. 2013), na camada de 0-20 cm, para caracterização química (Tabela 2). Na semeadura, foram aplicados $300 \mathrm{~kg} \mathrm{ha}^{-1}$ do fertilizante 4-30-16 $(\mathrm{N}-\mathrm{P}-\mathrm{K})+0,5 \% \mathrm{Zn}+0,4 \%$ B. No estádio fenológico V3 (três folhas completamente desenvolvidas), conforme escala de Marur \& Ruano (2001), foram aplicados $200 \mathrm{~kg} \mathrm{ha}^{-1}$ de 20-0-30 (N-P-K) + 0,2\% de $\mathrm{B}$, em uma única cobertura. Em todos os anos e épocas de semeadura, as adubações corresponderam a $52 \mathrm{~kg} \mathrm{ha}^{-1}$ de $\mathrm{N}, 90 \mathrm{~kg} \mathrm{ha}^{-1}$ de $\mathrm{P}_{2} \mathrm{O}_{5}$ e $108 \mathrm{~kg} \mathrm{ha}^{-1}$ de $\mathrm{K}_{2} \mathrm{O}$.

O manejo de inseticidas e fungicidas foi realizado de acordo com a necessidade, e seguiu o padrão de aplicação da lavoura comercial. No controle químico de plantas daninhas, foram aplicados os herbicidas diuron e s-metolacloro, em pré-emergência do algodoeiro, e, em pós-emergência, os graminicidas clethodim e haloxyfop-methyl e os latifolicidas pyrithiobac-sodium e trifloxysulfuron-sodium, nas doses registradas pelo fabricante para a cultura do algodoeiro. Para o controle de soja voluntária, quando necessário, foi realizada capina com enxada, em complemento aos herbicidas.

O manejo do regulador de crescimento foi realizado por meio de cloreto de mepiquat (CM). Em 2009, foram efetuadas três pulverizações: a primeira com $40 \mathrm{~g} \mathrm{ha}^{-1}$ do ingrediente ativo CM, quando as plantas de algodão atingiram altura de $35-40 \mathrm{~cm}$; a segunda e a terceira com $80 \mathrm{~g} \mathrm{ha}^{-1}$ e $120 \mathrm{~g} \mathrm{ha}^{-1}$ do ingrediente ativo $\mathrm{CM}$, respectivamente, em função da retomada do crescimento (Ferreira 2014). Em 2010 e 2011, só foi necessária uma aplicação com $40 \mathrm{~g} \mathrm{ha}^{-1}$.

Nas avaliações, foram consideradas como área útil as quatro linhas centrais da subparcela, cada linha apresentando 4,0 $\mathrm{m}$ de comprimento útil, isto é, excluindo-se $0,5 \mathrm{~m}$ das extremidades. Antes
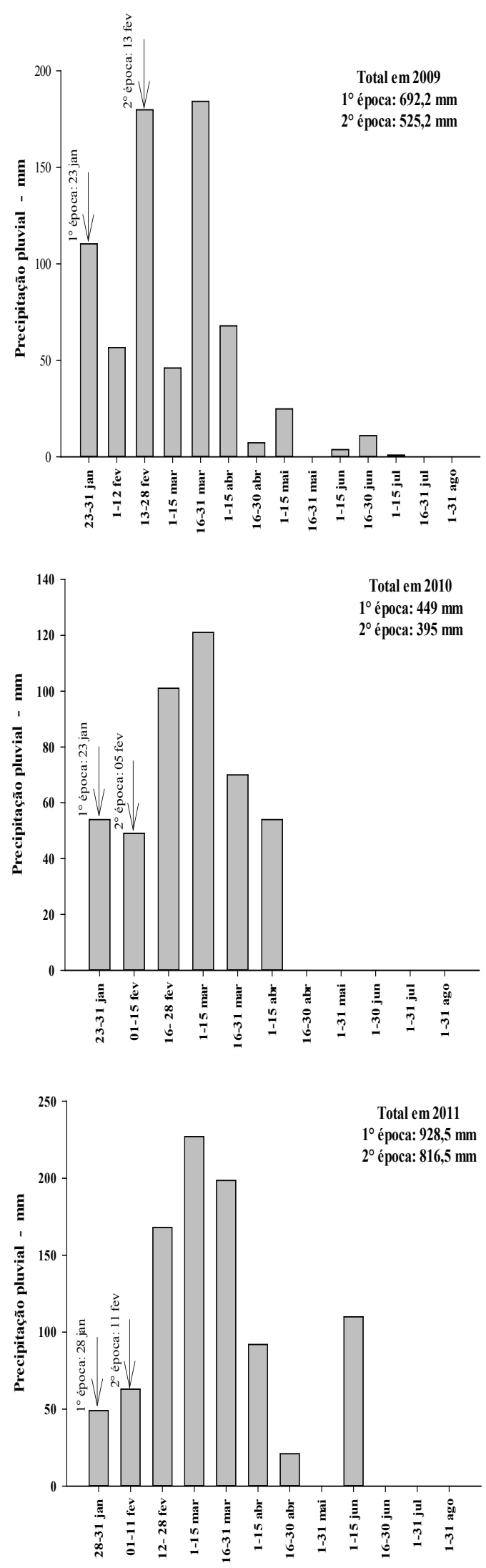

Figura 1. Precipitação pluvial (mm) durante a condução dos experimentos (Montividiu, GO). 
Tabela 2. Resultados da análise do solo nas camadas de 0-20 cm de profundidade, antes da instalação dos experimentos (Montividiu, $\mathrm{GO})$.

\begin{tabular}{|c|c|c|c|c|c|c|c|c|c|c|c|}
\hline \multirow{2}{*}{ Ano } & $\mathrm{pH}^{1}$ & $\mathrm{P}^{2}$ & $\mathrm{~K}^{3}$ & $\mathrm{Ca}^{4}$ & $\mathrm{Mg}^{5}$ & $\mathrm{Al}^{6}$ & $\mathrm{H}+\mathrm{Al}^{7}$ & $\mathrm{SB}^{8}$ & $\mathrm{CTC}^{9}$ & $\mathrm{~V}^{10}$ & M.O. ${ }^{11}$ \\
\hline & $\mathrm{CaCl}_{2}$ & \multicolumn{2}{|c|}{$\mathrm{mg} \mathrm{dm}^{-3}$} & \multicolumn{6}{|c|}{$\mathrm{cmol}_{\mathrm{c}} \mathrm{dm}^{-3}$} & $\%$ & $\mathrm{~g} \mathrm{~kg}^{-1}$ \\
\hline 2009 & 5,5 & 7,0 & 64 & 3,9 & 1,7 & 0 & 3,6 & 5,8 & 9,4 & 62 & 35 \\
\hline 2010 & 6,1 & 8,6 & 86 & 5,6 & 2,9 & 0 & 2,4 & 8,7 & 11,1 & 78 & 32 \\
\hline 2011 & 5,2 & 6,8 & 64 & 3,5 & 1,0 & 0 & 3,3 & 4,7 & 8,0 & 59 & 32 \\
\hline
\end{tabular}

${ }^{1} \mathrm{pH}$ em $\mathrm{CaCl}_{2}$, na relação solo:água $1: 2,5 ;{ }^{2}$ fósforo disponível; ${ }^{3}$ potássio $;{ }^{4}$ cálcio $;{ }^{5}$ magnésio; ${ }^{6}$ alumínio trocável; ${ }^{7}$ acidez potencial; ${ }^{8}$ soma de bases $=\mathrm{Ca}+\mathrm{Mg}+\mathrm{K} ;$ ${ }^{9}$ capacidade de troca de cátions $=\mathrm{H}+\mathrm{Al}+\mathrm{SB} ;{ }^{10}$ volume de saturação por bases trocáveis $=\mathrm{SB} / \mathrm{CTC} ;{ }^{11}$ matéria orgânica. Métodos: P, K, Ca e Mg - extração pela resina trocadora de íons; M.O. - dicromato/colorimetria (Van Raij et al. 1986).

da colheita, foi avaliada a população final, e foram coletados vinte capulhos no terço médio das plantas, para a determinação da porcentagem de fibra e da massa de um capulho. Em cinco plantas selecionadas ao acaso, foram determinados a altura de planta e o número de capulhos por planta, sendo este transformado para número de capulhos por área. A colheita foi realizada manualmente e os dados de produção da área útil transformados em $\mathrm{kg} \mathrm{ha}^{-1}$, para determinação da produtividade de fibra.

Os dados foram submetidos à análise de variância individual, sendo realizadas análises conjuntas das épocas nos três experimentos $(2009,2010$ e 2011), dado que os níveis dos fatores cultivar e densidade não foram comuns entre os anos. Para as variáveis cultivar e densidade de plantas, em 2010, foi utilizado o teste Tukey, a $5 \%$. Em 2009 e 2011, a variável quantitativa densidade de plantas foi submetida à análise de regressão polinomial, testando-se os modelos linear e quadrático, a $5 \%$.

\section{RESULTADOS E DISCUSSÃO}

Em 2009, entre a semeadura e a colheita, foram considerados 217 e 213 dias para a primeira e segunda época de semeadura, respectivamente. Em 2010, ano que choveu menos (Figura 1), o ciclo foi menor, sendo de 194 dias para a primeira época e 188 para a segunda. No ano de 2011, foram 203 e 199 dias, respectivamente para a primeira e segunda época de semeadura. A diferença inicial entre a primeira e segunda época de semeadura foi de 21, 13 e 14 dias, respectivamente para 2009, 2010 e 2011. Contudo, a diferença de ciclo para as duas épocas de semeadura foi de apenas 4, 6 e 4 dias, respectivamente em 2009, 2010 e 2011. Em virtude do término das precipitações pluviais, as plantas de algodão cessaram o desenvolvimento vegetativo e reprodutivo, reduzindo, com isso, o ciclo, na segunda época de semeadura.
A precocidade da planta de algodão é definida, principalmente, pelo menor intervalo de tempo decorrido entre as emissões das estruturas reprodutivas, nas diferentes posições da planta. A limitação por água, durante o desenvolvimento reprodutivo em 2010 e 2011, impediu que as plantas de algodão produzissem mais estruturas frutíferas, de modo que as cultivares não diferiram entre si, em relação ao ciclo.

$\mathrm{O}$ atraso na semeadura do algodão resultou em plantas $10 \mathrm{~cm}$ mais baixas (Tabelas 3, 4 e 5), em relação à semeadura na segunda quinzena de janeiro, nos três anos de condução do trabalho.

A altura de plantas foi influenciada significativamente pela cultivar, exceto em 2010, ano com menor precipitação pluvial. A BRS 293 foi $9,5 \mathrm{~cm}$ maior que a cultivar FM 966, em 2009, e 12,5 cm maior que a cultivar FMT 523, em 2011. A maior altura $(71,1 \mathrm{~cm})$ foi observada em 2009, para a BRS 293. Essas cultivares estudadas, em condições de safra e espaçamento tradicionais e com o uso de regulador de crescimento, normalmente, atingem, na colheita, altura entre $100 \mathrm{~cm}$ e $130 \mathrm{~cm}$ (Lamas \& Ferreira 2015). Portanto, esses resultados demonstram que ocorrem mudanças no padrão de crescimento do algodoeiro, quando cultivado no sistema adensado em segunda safra.

A densidade de plantas, outro fator estudado, não teve efeito sobre o crescimento do algodoeiro, exceto no primeiro ano (Tabela 3 ). Neste, como houve melhor distribuição das chuvas, as plantas cresceram mais com o aumento da densidade. A altura aumentou de forma linear $\left(\mathrm{y}=59,1+0,467^{* *} \mathrm{x} ; \mathrm{R}^{2}=\right.$ $0,92)$, com o aumento da densidade. Esse resultado difere dos observados por Jost \& Cothren (2000) e Clawson et al. (2006), os quais verificaram redução na altura, com o aumento da densidade de plantas. Entretanto, as cultivares, espaçamentos entre fileiras e condições de cultivo foram diferentes, em relação ao presente trabalho. 
Nos três anos, a população final de plantas de algodão, na época da colheita, só foi influenciada positivamente pela variável densidade de plantas (Tabelas 3, 4 e 5), o que era esperado, em virtude de a densidade ser uma fonte de variação em estudo. A interação entre as variáveis cultivar e densidade sobre a população de plantas só foi significativa em 2009, verificando-se efeito quadrático (Figura 2a) para a cultivar FM 966, com população máxima estimada de 161.385 plantas ha $^{-1}$, e efeito linear crescente (Figura 2a) para a BRS 293. No ano de 2011, observou-se efeito linear crescente da população final (Figura 2b).

Nos três experimentos, as maiores densidades iniciais do estudo não corresponderam à mesma população na colheita. Muitas plantas morreram,
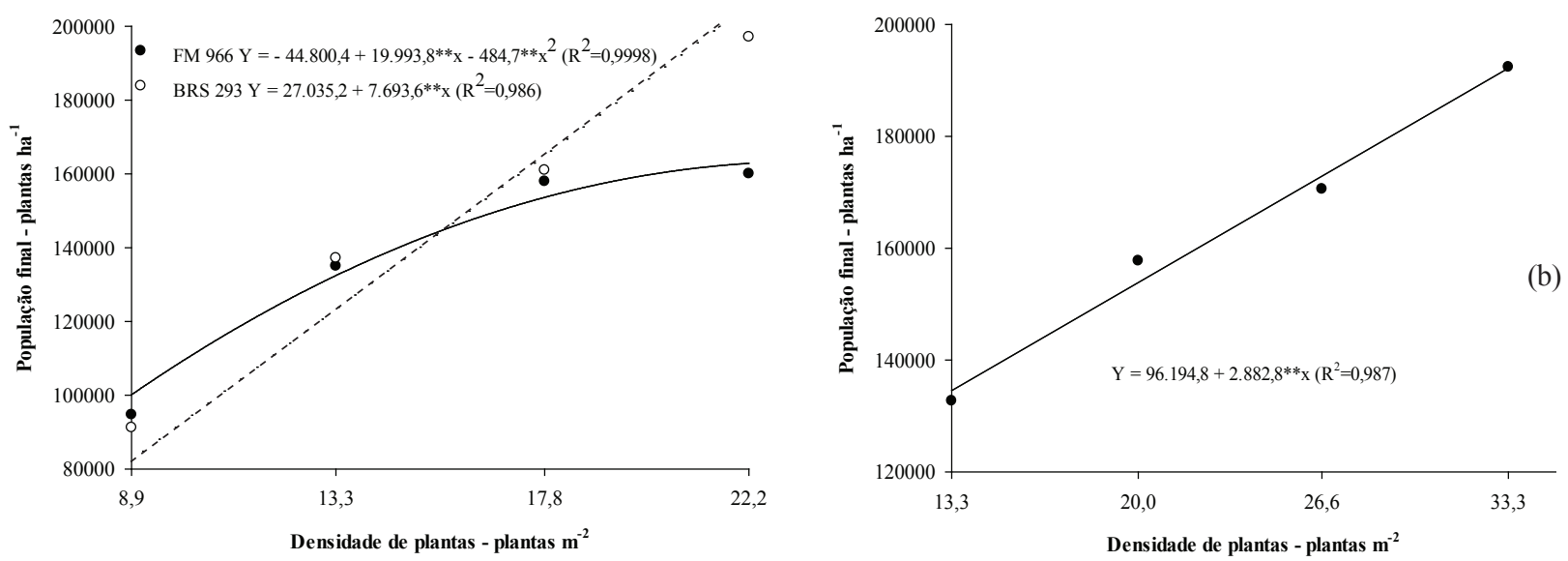

Figura 2. População final de plantas para as cultivares FM 966 e BRS 293, em 2009 (a), e para a média geral das cultivares (BRS 293 e FMT 523), em 2011 (b), em função da densidade de plantas de algodoeiro, em cultivo adensado de segunda safra (Montividiu, GO).

Tabela 3. Altura de planta (ALT), número de plantas ha ${ }^{-1}$ (POP), número de capulhos $\mathrm{m}^{-2}$ (NC), massa de um capulho (MC) e produtividade de fibra, em função de cultivares, épocas de semeadura e densidades de plantas, para o cultivo do algodoeiro no sistema adensado em segunda safra (Montividiu, GO, 2009).

\begin{tabular}{|c|c|c|c|c|c|}
\hline \multirow{2}{*}{ Época (E) } & ALT & POP & \multirow{2}{*}{$\mathrm{NC}$} & $\mathrm{MC}$ & Produtividade de fibra \\
\hline & $\mathrm{cm}$ & plantas ha-1 & & $\mathrm{g}$ & $\mathrm{kg} \mathrm{ha}^{-1}$ \\
\hline $23 / 01$ & $71,6 \mathrm{~A}$ & $142.952 \mathrm{~A}$ & $121,1 \mathrm{~A}$ & $6,3 \mathrm{~A}$ & $2.084 \mathrm{~A}$ \\
\hline $13 / 02$ & $61,1 \mathrm{~B}$ & $140.545 \mathrm{~A}$ & $70,7 \mathrm{~B}$ & $6,1 \mathrm{~A}$ & $1.567 \mathrm{~B}$ \\
\hline \multicolumn{6}{|l|}{ Cultivar (C) } \\
\hline FM 966 & $61,6 \mathrm{~b}$ & $136.903 \mathrm{a}$ & $87,3 \mathrm{~b}$ & $6,3 \mathrm{a}$ & $1.791 \mathrm{a}$ \\
\hline BRS 293 & $71,1 \mathrm{a}$ & $146.594 \mathrm{a}$ & $104,5 \mathrm{a}$ & $6,1 \mathrm{a}$ & $1.860 \mathrm{a}$ \\
\hline $\mathrm{E} \times \mathrm{C}(\operatorname{Pr}>\mathrm{F})$ & ns & ns & ns & $*$ & $\mathrm{~ns}$ \\
\hline CV1 $(\%)$ & 7,41 & 11,19 & 28,78 & 6,13 & 12,38 \\
\hline \multicolumn{6}{|l|}{ Densidade (D) } \\
\hline 8,9 & 62,6 & 92.924 & 68,5 & 6,1 & 1.679 \\
\hline 13,3 & 66,5 & 136.083 & 100,2 & 6,5 & 1.839 \\
\hline 17,8 & 67,0 & 159.444 & 106.3 & 6,0 & 1.869 \\
\hline 22,2 & 69,3 & 178.542 & 108,6 & 6,1 & 1.915 \\
\hline $\mathrm{D}(\operatorname{Pr}>\mathrm{F})$ & $* *$ & $* *$ & $* *$ & $* *$ & $*$ \\
\hline $\mathrm{C} \times \mathrm{D}(\mathrm{Pr}>\mathrm{F})$ & ns & $* *$ & $\mathrm{~ns}$ & $\mathrm{~ns}$ & $\mathrm{~ns}$ \\
\hline $\mathrm{E} \times \mathrm{D}(\operatorname{Pr}>\mathrm{F})$ & $\mathrm{ns}$ & $\mathrm{ns}$ & $\mathrm{ns}$ & $*$ & ns \\
\hline $\mathrm{C} \times \mathrm{E} \times \mathrm{D}(\operatorname{Pr}>\mathrm{F})$ & ns & ns & ns & ns & ns \\
\hline CV2 (\%) & 7,82 & 10,71 & 21,86 & 8,03 & 11,11 \\
\hline Média & 66,4 & 141.748 & 95,9 & 6,2 & 1.825 \\
\hline
\end{tabular}

ns, * e **: não significativo a $5 \%$ e significativo a $5 \%$ e $1 \%$, respectivamente, pelo teste F. Médias seguidas pela mesma letra maiúscula, na coluna, para o fator época, e minúscula, para o fator cultivar, não diferem significativamente entre si, pelo teste $\mathrm{t}(\mathrm{p}<0,05)$. 
Tabela 4. Altura de planta (ALT), número de plantas ha ${ }^{-1}$ (POP), número de capulhos $\mathrm{m}^{-2}$ (NC), massa de um capulho (MC) e produtividade de fibra, em função de cultivares, épocas de semeadura e densidades de plantas, para o cultivo de algodoeiro no sistema adensado em segunda safra (Montividiu, GO, 2010).

\begin{tabular}{|c|c|c|c|c|c|}
\hline \multirow{2}{*}{ Época (E) } & ALT & POP & \multirow{2}{*}{$\mathrm{NC}$} & $\mathrm{MC}$ & Produtividade de fibra \\
\hline & $\mathrm{cm}$ & plantas ha $\mathrm{h}^{-1}$ & & $\mathrm{~g}$ & $\mathrm{~kg} \mathrm{ha}^{-1}$ \\
\hline $23 / 01$ & $69,0 \mathrm{~A}$ & $166.111 \mathrm{~B}$ & $74,0 \mathrm{~A}$ & $5,1 \mathrm{~A}$ & $1.396 \mathrm{~A}$ \\
\hline $05 / 02$ & $60,9 \mathrm{~B}$ & $199.877 \mathrm{~A}$ & $76,9 \mathrm{~A}$ & $5,1 \mathrm{~A}$ & $1.159 \mathrm{~B}$ \\
\hline \multicolumn{6}{|l|}{ Cultivar (C) } \\
\hline FM 966 & 63,3 a & $191.759 \mathrm{a}$ & $76,1 \mathrm{a}$ & $5,2 \mathrm{a}$ & $1.338 \mathrm{a}$ \\
\hline FMT 523 & $63,3 \mathrm{a}$ & $173.148 \mathrm{a}$ & $73,4 \mathrm{a}$ & $4,8 \mathrm{~b}$ & $1.230 \mathrm{a}$ \\
\hline BRS 293 & $68,2 \mathrm{a}$ & $184.074 \mathrm{a}$ & $77,0 \mathrm{a}$ & $5,4 \mathrm{a}$ & $1.265 \mathrm{a}$ \\
\hline CV1 (\%) & 12,49 & 14,55 & 14,88 & 7,46 & 10,77 \\
\hline $\mathrm{E} \times \mathrm{C}(\operatorname{Pr}>\mathrm{F})$ & $\mathrm{ns}$ & $\mathrm{ns}$ & $\mathrm{ns}$ & ns & ns \\
\hline \multicolumn{6}{|l|}{ Densidade (D) } \\
\hline 17,8 & $64,8 \mathrm{a}$ & $174.028 \mathrm{~b}$ & $70,3 \mathrm{a}$ & $5,3 \mathrm{a}$ & $1.267 \mathrm{a}$ \\
\hline 24,4 & $63,8 \mathrm{a}$ & $187.083 \mathrm{ab}$ & $76.5 \mathrm{a}$ & $5,0 \mathrm{~b}$ & $1.285 \mathrm{a}$ \\
\hline 31,1 & $66,2 \mathrm{a}$ & $214.167 \mathrm{a}$ & $79,5 \mathrm{a}$ & $5,0 \mathrm{~b}$ & $1.281 \mathrm{a}$ \\
\hline $\mathrm{D}(\operatorname{Pr}>\mathrm{F})$ & ns & $* *$ & ns & $*$ & $\mathrm{~ns}$ \\
\hline $\mathrm{C} \times \mathrm{D}(\operatorname{Pr}>\mathrm{F})$ & ns & $\mathrm{ns}$ & ns & ns & ns \\
\hline $\mathrm{E} \times \mathrm{D}(\operatorname{Pr}>\mathrm{F})$ & ns & $\mathrm{ns}$ & ns & $\mathrm{ns}$ & $\mathrm{ns}$ \\
\hline $\mathrm{C} \times \mathrm{E} \times \mathrm{D}(\mathrm{Pr}>\mathrm{F})$ & ns & ns & ns & ns & ns \\
\hline CV2 (\%) & 7,38 & 13,70 & 19,52 & 6,13 & 13,24 \\
\hline Média & 64,9 & 182.994 & 75,5 & 5,1 & 1.278 \\
\hline
\end{tabular}

Tabela 5. Altura de planta (ALT), número de plantas ha $\mathrm{a}^{-1}$ (POP), número de capulhos $\mathrm{m}^{-2}$ (NC), massa de um capulho (MC) e produtividade de fibra, em função de cultivares, épocas de semeadura e densidades de plantas, para o cultivo do algodoeiro no sistema adensado em segunda safra (Montividiu, GO, 2011).

\begin{tabular}{|c|c|c|c|c|c|}
\hline \multirow{2}{*}{ Época (E) } & ALT & POP & \multirow{2}{*}{$\mathrm{NC}$} & $\mathrm{MC}$ & Produtividade de fibra \\
\hline & $\mathrm{cm}$ & plantas ha-1 & & $\mathrm{g}$ & $\mathrm{kg} \mathrm{ha}^{-1}$ \\
\hline $28 / 01$ & $55,4 \mathrm{~A}$ & $167.112 \mathrm{~A}$ & $83,7 \mathrm{~A}$ & $6,5 \mathrm{~A}$ & $1.231 \mathrm{~A}$ \\
\hline $11 / 02$ & $45,1 \mathrm{~B}$ & $159.616 \mathrm{~A}$ & $58,6 \mathrm{~B}$ & $5,9 \mathrm{~A}$ & $720 \mathrm{~B}$ \\
\hline \multicolumn{6}{|l|}{ Cultivar (C) } \\
\hline FMT 523 & $44,0 \mathrm{~b}$ & $162.103 \mathrm{a}$ & $64,2 \mathrm{~b}$ & $6,2 \mathrm{a}$ & $932 \mathrm{a}$ \\
\hline BRS 293 & $56,5 \mathrm{a}$ & $164.626 \mathrm{a}$ & $78,1 \mathrm{a}$ & $6,2 \mathrm{a}$ & $1.020 \mathrm{a}$ \\
\hline $\mathrm{E} \times \mathrm{C}(\operatorname{Pr}>\mathrm{F})$ & $\mathrm{ns}$ & $\mathrm{ns}$ & $\mathrm{ns}$ & $\mathrm{ns}$ & $*$ \\
\hline CV1 (\%) & 16,73 & 9,11 & 30,82 & 19,14 & 14,87 \\
\hline \multicolumn{6}{|l|}{ Densidade (D) } \\
\hline 13,3 & 51,8 & 132.697 & 63,2 & 7,0 & 1.008 \\
\hline 20,0 & 49,9 & 157.766 & 73,8 & 6,3 & 993 \\
\hline 26,6 & 48,9 & 170.598 & 70,9 & 5,7 & 970 \\
\hline 33,3 & 50,3 & 192.397 & 76,6 & 5,9 & 930 \\
\hline $\mathrm{D}(\operatorname{Pr}>\mathrm{F})$ & $\mathrm{ns}$ & $* *$ & $\mathrm{~ns}$ & $*$ & $\mathrm{~ns}$ \\
\hline $\mathrm{C} \times \mathrm{D}(\mathrm{Pr}>\mathrm{F})$ & $\mathrm{ns}$ & $\mathrm{ns}$ & $\mathrm{ns}$ & ns & ns \\
\hline $\mathrm{E} \times \mathrm{D}(\operatorname{Pr}>\mathrm{F})$ & ns & ns & ns & $\mathrm{ns}$ & ns \\
\hline $\mathrm{C} \times \mathrm{E} \times \mathrm{D}(\operatorname{Pr}>\mathrm{F})$ & ns & $\mathrm{ns}$ & ns & ns & ns \\
\hline CV2 (\%) & 11,70 & 10,65 & 26,88 & 17,05 & 17,20 \\
\hline Média & 50,2 & 163.364 & 71,1 & 6,2 & 975 \\
\hline
\end{tabular}


sobretudo as menos vigorosas, em função da grande competição por luz, nutrientes e, principalmente, água. As mais altas densidades de plantas não incrementaram a produtividade do algodoeiro cultivado em segunda safra, exceto para o experimento de 2009. Provavelmente, essa resposta positiva da produtividade em função da elevação da densidade de plantas decorreu da intensidade e frequência das chuvas durante os meses de maio e junho de 2009 (Figura 1), possibilitando maior retenção de capulhos por planta e por área (Tabela 3). Em 2011, apesar da maior precipitação pluvial, não houve adequada distribuição das chuvas. Nesse ano, foram quase sessenta dias sem chuva durante a fase de desenvolvimento reprodutivo, comprometendo o potencial produtivo, mesmo nas maiores densidades de plantas.

$\mathrm{O}$ atraso na semeadura, sendo ela realizada em 13 de fevereiro de 2009 (Tabela 3) e 11 de fevereiro de 2011 (Tabela 5), resultou na diminuição do número de capulhos por área e na produtividade de fibra, esta também reduzindo-se em 2010 (Tabela 4). As diferenças de produtividade de fibra, entre a primeira e segunda época de semeadura, foram de $517 \mathrm{~kg} \mathrm{ha}^{-1}$ em 2009, $237 \mathrm{~kg} \mathrm{ha}^{-1}$ em 2010 e $511 \mathrm{~kg} \mathrm{ha}^{-1}$ em 2011. Assim, a produtividade de fibra diminuiu cerca de $25 \%, 17 \%$ e $41 \%$, respectivamente em 2009 , 2010 e 2011. Essa perda de produtividade ocorre em função da semeadura tardia, realizada na primeira quinzena de fevereiro. Esses resultados indicam que poucos dias de atraso na semeadura, ou seja, 21 dias em 2009, 13 dias em 2010 e 14 dias em 2011, foram extremamente prejudiciais à produtividade do algodoeiro, e isso está relacionado à menor disponibilidade hídrica.

De acordo com Grimes \& El-Zik (1990), para alcançar alta produtividade, é necessário que o algodoeiro receba pelo menos $700 \mathrm{~mm}$ de água, durante o seu ciclo. No primeiro, segundo e terceiro anos do presente trabalho, os algodoeiros semeados na segunda quinzena de janeiro receberam $692 \mathrm{~mm}$, $449 \mathrm{~mm}$ e $929 \mathrm{~mm}$ de água, respectivamente, enquanto os algodoeiros semeados na primeira quinzena de fevereiro receberam $525 \mathrm{~mm}, 395 \mathrm{~mm}$ e $817 \mathrm{~mm}$ (Figura 1). Em 2011, apesar de a precipitação pluvial ter ultrapassado $800 \mathrm{~mm}$, sua distribuição foi muito irregular, e durante o pico de florescimento e frutificação, período de grande demanda hídrica pela planta, foram sessenta dias sem chuva, resultando em intenso aborto de estruturas reprodutivas, conse- quentemente formando poucos capulhos por área e produzindo menos fibra (Tabela 5). De acordo com Hake \& Grimes (2010), Loka et al. (2011) e Yeates (2014), o período de maior necessidade de água e fotoassimilados do algodoeiro está entre a primeira flor aberta até a abertura do primeiro capulho, devido à intensa demanda para a formação das sementes e das fibras.

Não houve diferença significativa entre as cultivares, para a produtividade de fibra (Tabelas 3 , 4 e 5), ou seja, as cultivares tiveram desempenhos agronômicos similares nas diferentes condições ambientais, durante o cultivo adensado em segunda safra. Em 2011, observou-se interação significativa entre época de semeadura e cultivar sobre a produtividade de fibra. Após o desdobramento da interação (Tabela 6), fixando-se o fator cultivar, a produtividade de fibra da FMT 523, na primeira época de semeadura, foi superior em $367 \mathrm{~kg} \mathrm{ha}^{-1}$, em relação à segunda época, enquanto, para a BRS 293, a diferença foi de $657 \mathrm{~kg} \mathrm{ha}^{-1}$. Quando a semeadura para o cultivo em segunda safra foi atrasada, a redução percentual de produtividade foi maior na cultivar de ciclo médio, em comparação com a cultivar de ciclo precoce. Fixando-se a primeira época de semeadura, a produtividade de fibra da BRS 293, de ciclo médio, foi maior em $233 \mathrm{~kg} \mathrm{ha}^{-1}$, em relação à cultivar FMT 523 (Tabela 6). Na segunda época de semeadura, não houve diferença de produtividade entre as cultivares. Assim, observa-se que, para o cultivo adensado em segunda safra, com semeadura na segunda quinzena de janeiro, o uso de cultivar de ciclo e porte médios apresentou produtividade de fibra igual (Tabelas $3 \mathrm{e}$ 4) ou superior (Tabelas 5 e 6), em relação às cultivares de ciclo precoce. Em semeaduras mais tardias, a cultivar não foi determinante na expressão do potencial de produtividade de fibra.

A massa de um capulho, em 2009, foi afetada significativamente pela interação entre a época de

Tabela 6. Desdobramento da interação entre cultivar e época de semeadura, para a produtividade de fibra $\left(\mathrm{kg} \mathrm{ha}^{-1}\right)$ de algodoeiro no sistema adensado em segunda safra (Montividiu, GO, 2011).

\begin{tabular}{lcc}
\hline \multirow{2}{*}{ Cultivar } & \multicolumn{2}{c}{ Época de semeadura } \\
\cline { 2 - 3 } & $28 / 01$ & $11 / 02$ \\
\hline FMT 523 & $1.115 \mathrm{Ab}$ & $748 \mathrm{Ba}$ \\
BRS 293 & $1.348 \mathrm{Aa}$ & $691 \mathrm{Ba}$ \\
\hline
\end{tabular}

Médias seguidas pela mesma letra maiúscula, na linha, e minúscula, na coluna, não diferem significativamente entre si, pelo teste $\mathrm{t}(\mathrm{p}<0,05)$. 
semeadura e a cultivar. Na primeira época de semeadura, a FM 966 apresentou massa de um capulho $6,6 \%$ superior, em relação à semeadura na primeira quinzena de fevereiro, enquanto a BRS 293 não diferiu significativamente entre as duas épocas.

Em 2009, a produtividade de fibra aumentou linearmente com a densidade de plantas (Figura 3) e o número de capulhos por área aumentou de forma quadrática, alcançando o máximo estimado na densidade de 19,5 plantas $\mathrm{m}^{-2}$.

Silva et al. (2006), ao estudarem o algodoeiro semeado nos espaçamentos entre fileiras de $0,38 \mathrm{~cm}, 0,76 \mathrm{~cm}$ e $0,95 \mathrm{~cm}$, e com 5 plantas $\mathrm{m}^{-1}$, 8 plantas $\mathrm{m}^{-1}, 11$ plantas $\mathrm{m}^{-1}$ e 14 plantas $\mathrm{m}^{-1}$, observaram que o número de ramos frutíferos por planta e o número de internódios diminuíram com o aumento da população de plantas, mas que esse efeito foi compensado pelo aumento do número de ramos frutíferos por área.

De acordo com Boquet (2005), em condições de alta população de plantas, há redução no número de capulhos por planta, entretanto, o número de capulhos por área aumenta, não interferindo na produtividade. À medida que a densidade de plantas aumenta, eleva-se o sombreamento na parte inferior das plantas de algodão, resultando em maior apodrecimento de maçãs (York 1983) e abscisão de frutos (Bednarz et al. 2000).

Em 2010 e 2011, não houve aumento de produtividade com as variações da população de plantas, assim como observado por Jost \& Cothren (2001), Clawson et al. (2006) e Silva et al. (2011).

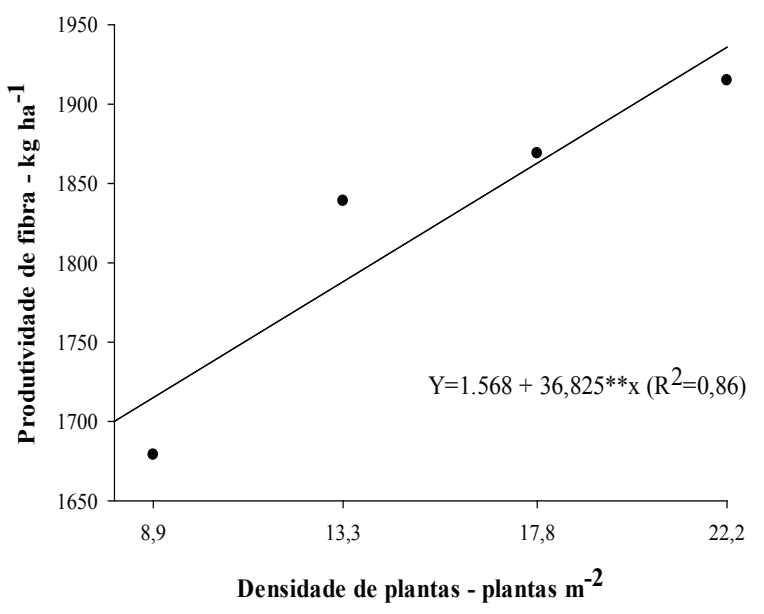

De acordo com Heitholt \& Sassenrath-Cole (2010), alta densidade de plantas pode exaurir a água disponível no solo, restringindo, com isso, o desenvolvimento reprodutivo, sobretudo o enchimento de maçãs.

De modo geral, observou-se que, com a variação das densidades de plantas de 8,9-33,3 plantas $\mathrm{m}^{-2}$, houve nítido poder de compensação dos componentes de produção do algodoeiro. Em anos com adequada precipitação pluvial, acompanhada da sua boa distribuição durante o ciclo do algodoeiro, pode-se cultivá-lo, em segunda safra, com população aproximada de 178.000 plantas ha $^{-1}$. Porém, caso a previsão seja de poucas chuvas, ou com déficit hídrico durante o desenvolvimento reprodutivo do algodoeiro, pode-se trabalhar com populações menores, por volta de 132.000 plantas ha $^{-1}$.

As cultivares de ciclo precoce e médio pouco influenciaram na produtividade, no sistema de cultivo adensado em segunda safra. Todas as cultivares apresentaram redução de porte e produtividade, quando a semeadura foi na primeira quinzena de fevereiro.

O principal fator determinante para o sucesso do algodão cultivado adensado em segunda safra foi a época de semeadura, que, realizada na segunda quinzena de janeiro, resultou em melhor performance produtiva. Os resultados ratificam a importância do adequado planejamento para a semeadura, cultivo e colheita da soja, no mínimo espaço de tempo possível, de modo que não atrase a semeadura do algodão e comprometa a sua produtividade.

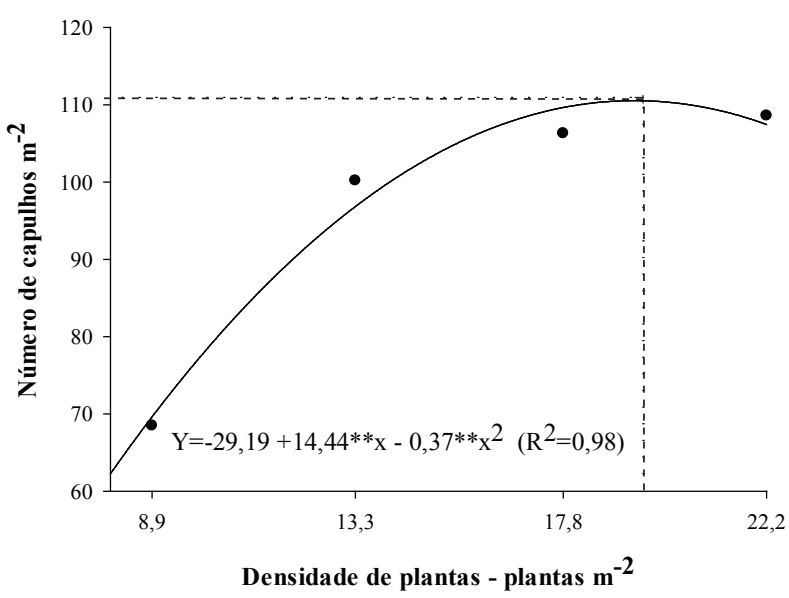

Figura 3. Produtividade de fibra e número de capulhos $\mathrm{m}^{-2}$, em função da densidade de plantas de algodoeiro, em cultivo adensado de segunda safra (Montividiu, GO, 2009). 


\section{CONCLUSÕES}

1. A semeadura tardia do algodão, na primeira quinzena de fevereiro, reduz a altura de planta, número de capulhos por área e produtividade de fibra.

2. Cultivares de ciclo precoce e médio se adequam melhor ao cultivo adensado em segunda safra.

3. O aumento da densidade de plantas não eleva a produtividade de fibra do algodoeiro cultivado em segunda safra, no espaçamento de $45 \mathrm{~cm}$ entre as fileiras, exceto quando as condições hídricas são favoráveis para o desenvolvimento reprodutivo.

\section{REFERENCIAS}

BEDNARZ, C. W.; BRIDGES, D. C.; BROWN, S. M. Analysis of cotton yield stability across population densities. Agronomy Journal, Madison, v. 92, n. 1, p. 128135, 2000.

BOQUET, D. J. Cotton in ultra-narrow spacing: plant density and nitrogen fertilizer rates. Agronomy Journal, Madison, v. 97, n. 1, p. 279-287, 2005.

CLAWSON, E. L.; COTHREN, J. T.; BLOUIN, D. C. Nitrogen fertilization and yield of cotton in ultra-narrow and conventional row spacings. Agronomy Journal, Madison, v. 98, n. 1, p. 72-79, 2006.

FERREIRA, A. C. de B. Fitorreguladores de crescimento em algodoeiro. Campina Grande: Embrapa Algodão, 2014. (Comunicado técnico, 373).

GRIMES, D. W.; EL-ZIK, K. M. Cotton. In: STEWART, B. A.; NIELSEN, D. R. (Eds.). Irrigation of agricultural crops. Madison: American Society of Agronomy, 1990. p. 741-773.

HAKE, K. D.; GRIMES, D. W. Crop water management to optimize growth and yield. In: STEWART, J. M. et al. (Ed.). Physiology of cotton. Dordrecht: Springer, 2010. p. 255-264.

HEITHOLT, J. J.; SASSENRATH-COLE, G. F. Inter-plant competition: growth responses to plant density and row spacing. In: STEWART, J. M. et al. (Ed.). Physiology of cotton. Dordrecht: Springer, 2010. p. 179-186.

INSTITUTO MATO-GROSSENSE DE ECONOMIA AGROPECUÁRIA (IMEA). $4^{a}$ estimativa de safra 2014/15: algodão. 2015. Disponível em: <http://www. imea.com.br/upload/publicacoes/arquivos/R104_4a_ Estimativa_de_Safra_Algodao_14-15_set15.pdf $>$. Acesso em: 23 out. 2015.

JOST, P. H.; COTHREN J. T. Growth and yield comparisons of cotton planted in conventional and ultra- narrow row spacings. Crop Science, Madison, v. 40, n. 2, p. 430-435, 2000.

JOST, P. H.; COTHREN, J. T. Phenotypic alterations and crop maturity differences in ultra-narrow row and conventionally spaced cotton. Crop Science, Madison, v. 41, n. 4, p. 1150-1159, 2001.

LAMAS, F. M. et al. Espaçamentos reduzidos na cultura do algodoeiro em Mato Grosso do Sul: I. Efeitos nas características de produção. Revista Brasileira de Oleaginosas e Fibras, Campina Grande, v. 9, n. 1/3, p. 903-914, 2005.

LAMAS, F. M.; FERREIRA, A. C. de B. Reguladores de crescimento, desfolhantes e maturadores. In: FREIRE, E. C. (Ed.). Algodão no Cerrado do Brasil. 3. ed. Brasília, DF: Abrapa, 2015. p. 559-582.

LOKA, D. A.; OOSTERHUIS, D. M.; RITCHIE, G. L. Water-deficit stress in cotton. In: OOSTERHUIS, D. M. (Ed.). Stress physiology in cotton. Cordova: The Cotton Foundation, 2011. p. 37-72.

MARUR, C. J.; RUANO, O. A reference system for determination of cotton plant development. Revista de Oleaginosas e Fibrosas, Campina Grande, v. 5, n. 2, p. 243-247, 2001.

SANTOS, H. G. dos et al. Sistema brasileiro de classificação de solos. 3. ed. Brasília, DF: Embrapa, 2013.

SILVA, A. V. et al. Crescimento e desenvolvimento do algodoeiro em diferentes configurações de semeadura. Bragantia, Campinas, v. 65, n. 3, p. 407-411, 2006.

SILVA, A. V. et al. Configurações de semeadura sobre a produção e a qualidade da fibra do algodoeiro. Semina: Ciências Agrárias, Londrina, v. 32, n. 4, p. 1709-1716, 2011.

VAN RAIJ, B.; QUAGGIO, J. A.; SILVA, N. M. Extraction of phosphorus potassium calcium and magnesium from soils by an ion-exchange resin procedure. Communications in Soil Science and Plant Analysis, New York, v. 17, n. 5, p. 547-566, 1986.

WELLS, R.; STEWART, A. M. Morphological alterations in response to management and environment. In: STEWART, J. M. et al. (Ed.). Physiology of cotton. Dordrecht: Springer, 2010. p. 24-32.

YEATES, S. Efeitos do estresse hídrico na fisiologia do algodoeiro. In: ECHER, F. R. (Ed.). O algodoeiro e os estresses abióticos: temperatura, luz, água e nutrientes. Cuiabá: Instituto Mato-Grossense do Algodão, 2014. p. 63-77.

YORK, A. C. Cotton cultivar response to mepiquat chloride. Agronomy Journal, Madison, v. 75, n. 3, p. 663667, 1983. 